\title{
CATÁLOGO SISTEMÁTICO DO PÓLEN DAS PLANTAS ARBÓREAS DO BRASIL MERIDIONAL. XXX: MELIACEAE
}

\author{
ORTRUD MONIKA BARTH, RONALDO LAURIA JUSTO e \\ MARCIA AGUIAR DE BARROS \\ Laboratório de Palinologia, Departamento de Botânica, Instituto de Biologia, CCS, UFRJ, Cidade Universitária, \\ CEP 21949-900, Rio de Janeiro, RJ, Brasil \\ Correspondência para: Ortrud Monika Barth, Instituto Oswaldo Cruz, Departamento de Virologia, \\ Av. Brasil, 4365, CEP 21045-900, Rio de Janeiro, RJ, Brasil \\ Recebido em 29/11/96 - Aceito em 02/06/98 - Distribuído em 28/08/98
}

(Com 4 esquemas e 68 figuras)

\section{ABSTRACT \\ Sistematic catalogue of arboreal plant pollen grains of southern Brazil. XXX: Meliaceae}

The pollen grain morphology of 16 species of the family Meliaceae is described. The pollen types established are in accordance to the genera based upon the pollen grain shape and aperture configuration. The surface ornamentation of the pollen grains of Cabralea canjerana canjerana only may be characterized. The most important morphological features of the pollen grains of the studied species are: the difficulty to visualize the boundary between sexine and nexine- 1 of some genera; the evidence of nexine-2; the non-variability of nexine-2 thickness; the increase of sexine and nexine-1 thickness in apertural areas; a fine surface ornamentation of the pollen grains.

Key words: pollen catalogue, pollen morphology, Meliaceae.

\section{RESUMO}

Foi analisada a morfologia polínica de 16 espécies da família Meliaceae. A distinção dos tipos polínicos ocorre em nível genérico, principalmente através da forma dos grãos de pólen, da ornamentação das superfícies e da forma das aberturas. Somente os grãos de pólen de Cabralea canjerana canjerana podem ser caracterizados pela ornamentação da superfície. Como características marcantes em todas as espécies estudadas, destacam-se: sexina e nexina-1 não bem delimitadas em alguns gêneros, em contrapartida ao destaque da nexina-2; a invariabilidade da espessura das nexinas-2; o espessamento da sexina e da nexina-1 nas regiões aperturais, a ornamentação delicada da superfície dos grãos de pólen.

Palavras-chave: catálogo de pólen, morfologia polínica, Meliaceae.

\section{INTRODUÇÃO}

A família Meliaceae pertence à ordem Sapindales (segundo Cronquist, 1988), compreendendo cerca de 5 gêneros e 120 espécies distribuídos por toda a Região Neotropical. 16 espécies agrupadas em 4 gêneros ocorrem como espécies arbóreas e nativas na Região Sul do Brasil (Klein, 1984).

O hábito da família constitui-se de árvores (medindo em média de 20 a $30 \mathrm{~m}$ de altura) e arvoretas (medindo em média de 3 a $10 \mathrm{~m}$ de altu- ra). São comuns nas Florestas Estacionais Deciduais e Semideciduais, apresentando ampla e expressiva distribuição. Ocorrem também na Floresta Ombrófila Densa da Encosta Atlântica, mesmo em altitudes elevadas. Sua maior concentração é no Sul do Brasil (Klein. 1984).

Apesar desta ser uma das famílias produtoras de madeira economicamente mais importantes do mundo, graças às suas excelentes propriedades e relativa facilidade de cultura em florestas artificiais, sua taxonomia ainda não é satisfatoriamente definida (Klein, 1984). 
Os gêneros mais estudados quanto à morfologia polínica são Cedrela e Trichilia (Erdtman, 1952; Ferreira \& Salgado-Labouriau, 1966; Palácios, 1968; Markgraf \& D'Antoni, 1978; Bonnefille \& Riollet, 1980; Carreira \& Secco, 1984; Roubik \& Moreno, 1991; Silvestre-Capelato et al., 1996). Dentre estes autores destaca-se a tentativa de Erdtman (1952) de subdividir a família em três subfamílias através do uso da morfologia polínica.

O objetivo do presente trabalho é conhecer a morfologia polínica de espécies arbóreas da família Meliaceae da Região Sul do Brasil, fazendo uso da microscopia de luz e da microscopia eletrônica de varredura.

\section{MATERIAL E MÉTODOS}

O material é proveniente de exsicatas dos seguintes herbários: Herbário Instituto de Conservação da Natureza (GUA), Rio de Janeiro; Herbário Barbosa Rodrigues (HBR), Itajaí, Santa Catarina; Divisão de Botânica do Museu Nacional (R), Rio de Janeiro; Jardim Botânico do Rio de Janeiro (RB), Rio de Janeiro; e Herbário do Laboratório de Palinologia, Rio de Janeiro.

\section{MATERIAL EXAMINADO}

\section{Cabralea canjerana (Vellozo) Martius} subsp. canjerana: G. Martinelli e J. Hatton 10088 (X.1984) (GUA);

Cedrela fissilis Vellozo: SANTA CATARINA, Brusque, Mata da Azambuja, H. P. Veloso 115 (2.XII.1949), det. L. B. Smith (Lab. de Palinologia);

Cedrela lilloi $\boldsymbol{C}$. de Candolle: SANTA CATARINA, São Miguel d'Oeste, Canela Gaúcha, $8 \mathrm{Km}$ noroeste de São Miguel d'Oeste, L. B. Smith e R. M. Klein 14153 (19.XII.1964), det. T. D. Pennington (1981) (HBR):

Cedrela odorata Linnaeus: RIO DE JANEIRO, cultivada no Jardim Zoológico do Rio de Janeiro, Lanna-Sobrinho 1282 (19.X.1966), det. Humberto de S. Barreiros (1976) (RB).

Guarea kunthiana Adrien de Jussieu: PARAGUAI, Centro de Demonstración Florestal, Pto. Pte. Stroissner, R. M. Klein e J. A. Lopez 9310 (29.I.1971), det. R. M. Klein (1983) (HBR);

Guarea macrophylla Vahl. subsp. spicaeflora (Adr. Jussieu): PROVÍNCIA RIO DE JANEIRO, Rio Parayba, Netto, Moreira, Glaziou e Schwache s/nํ(29.II.1880), det. Humberto Barreiros (1981) (R);

Guarea macrophylla Vahl. subsp. tuberculata (Vellozo) Pennington: SANTA CATARINA, Brusque, Mata São Pedro, H. P. Veloso 87 (1.XII.1949), det. L. B. Smith (Lab. de Palinologia);

Trichilia casaretti $C$. de Candolle: SANTA CATARINA, Brusque, Mata São Pedro, H. P. Veloso 125 (2.XII.1949), det. L. B. Smith (Lab. de Palinologia);

Trichilia catigua Adr. Jussieu: SANTA CATARINA, São Miguel d'Oeste, Peperi, Paraíso, R. M. Klein 5113 (1.III.1964), det. T. D. Pennington (1981) (HBR);

Trichilia clausseni C. de Candolle: SANTA CATARINA, Porto União, São Miguel, R. M. Klein 3623 (9.XII.1962), det. T. D. Pennington (1981) (HBR);

Trichilia elegans Adr. Jussieu subsp. elegans: SANTA CATARINA, Catanduvas, 17-19 $\mathrm{km}$ oeste de Joaçaba, L. B. Smith e R. M. Klein 13948 (15.XII.1964), det. T. D. Pennington (1981) (HBR);

Trichilia lepidota Martius subsp. schumanniana (Harms) Pennington: SANTA CATARINA, Florianópolis, Ilha de Santa Catarina, Morro da Costa da Lagoa, R. M. Klein 7106 (17.I.1967), det. R. M. Klein (1983) (HBR);

Trichilia pallens $\boldsymbol{C}$. de Candolle: SANTA CATARINA, Rio do Sul, Serra do Matador, Reitz e Klein 7637 (25.XI.1958), det. T. D. Pennington (1981) (HBR);

Trichilia pallida Swartz: PARANÁ, Floresta, perto da cidade, Reitz e Klein 12037 (25.I.1962), det. T. D. Pennington (1981) (HBR);

Trichilia pseudostipularis (Adr. Jussieu) C. de Candolle: ESPÍRITO SANTO, Rio Doce (margem direita), Fazenda Gigante, E. A. Bueno e Luiz Emydio 204 (15.VII.1942), det. Humberto Barreiros (1985) (R);

Trichilia silvatica $C$. de Candolle: ESPÍRITO SANTO, Goitacazes, Rio Doce, J. G. Kuhlmann 6481 (19.X1.1943), det. T. D. Pennington (1985) (RB).

O material herborizado foi tratado pelo método padrão de acetólise (Erdtman, 1952), com a montagem das lâminas em gelatina glicerinada e lutagem com parafina, destinadas a observações em microscopia de luz (ML). 
Para a medida dos eixos polar e equatorial dos grãos de pólen, foram mensurados 25 grãos aleatoriamente distribuídos em 3 lâminas por taxa. Para o cálculo da média de cada parâmetro, utilizou-se o cálculo da média aritmética com o método do desvio padrão da média.

Os demais parâmetros padrões de medida (camadas da exina, comprimento do colpo, altura e largura da endoabertura) foram obtidos das medidas de 10 grãos aleatórios, distribuídos pelas 3 lâminas por taxa; para o cálculo da média, utilizou-se a média aritmética. As espessuras das camadas componentes da exina foram medidas sempre nas regiões polares dos grãos de pólen, as quais se apresentam mais regulares, não recebendo interferência dos espessamentos que ocorrem em volta das áreas aperturais.

O cálculo da razão do eixo polar pelo eixo equatorial $(\mathrm{P} / \mathrm{E})$ foi utilizado para caracterização dos grãos de pólen quanto à sua forma, quando isopolares e de simetria radial.

Para as observações em microscopia eletrônica de varredura (MEV), o material polínico acetolisado foi transferido para etanol a $70 \%$ e posteriormente seco sobre os suportes do microscópio eletrônico; foi coberto com ouro e observado em um aparelho Zeiss DSM-940 do Instituto Oswaldo Cruz, FIOCRUZ.

A descrição dos grãos de pólen segue o padrão estabelecido nas publicações mais recentes do "Catálogo" (Barros \& Barth, 1994; Scheel \& Barth, 1995).

A terminologia baseia-se no Glossário Ilustrado de Palinologia (Barth \& Melhem, 1988).
Abreviações
A - altura da endoabertura
amb - âmbito
C - comprimento do colpo
$\mathrm{E}$ - eixo equatorial (em vista equatorial)
$\mathrm{L}$ - largura da endoabertura
MEV - microscopia eletrônica de varredura

ML - microscopia de luz

$\mathrm{N} 1$ - espessura da nexina-1 (medida na área polar)

N2 - espessura da nexina-2 (medida na área polar)

$\mathrm{P}$ - eixo polar (em vista equatorial)

$\mathrm{P} / \mathrm{E}$ - razão entre o eixo polar e o eixo equatorial

$\mathrm{S}$ - espessura da sexina (medida na área polar)

\section{RESULTADOS}

\section{Gênero Cabralea}

Cabralea canjerana (Vellozo) Martius subsp. canjerana (Esquema 1, Figs. 1 a 6)

Forma do pólen: grãos de tamanho médio; simetria radial; isopolares; prolato esferoidais; amb circular a quadrangular de vértices arredondados; 4 - colporados; colpos estreitos; endoaberturas lalongadas, com ânulo; superfície finamente verrugosa; orbículos ausentes nas preparações acetolisadas.

Estratificação da exina: a sexina é perfurada por pontos que muitas vezes se anastomosam formando curtas canaletas, simples ou bifurcadas; a superfície da sexina é ondulada; columelas são indistintas; a nexina compreende a nexina-1 de espessura variável, responsável pela formação do ânulo em volta da endoabertura, e a nexina- 2 de espessura constante.

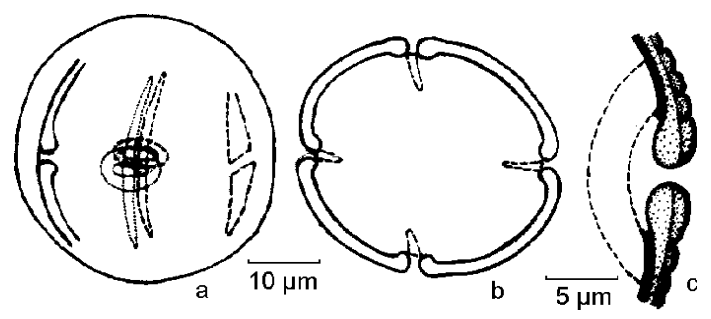

Esquema 1 - Cabralea canjerana: (a) vista equatorial: aberturas; (b) vista polar: amb, aberturas e corte óptico; (c) corte transversal pela exina e pelo centro de uma abertura.

TABELA 1

Gênero Cabralea : dimensões e forma dos grãos de pólen (em $\mu \mathrm{m})$ do espécimen examinado.

\begin{tabular}{|l|c|c|c|c|c|c|c|c|c|}
\hline Nome da espécie & $\mathbf{P}$ & $\mathbf{E}$ & $\mathbf{P} / \mathbf{E}$ & Forma & $\mathbf{C}$ & $\mathbf{L}$ & $\mathbf{A}$ & $\mathbf{S}+\mathbf{N 1}$ & $\mathbf{N 2}$ \\
\hline $\begin{array}{l}\text { Cabralea canjerana } \\
\text { canjerana }\end{array}$ & $33,1 \pm 0,9(25,6-42,6)$ & $31,7 \pm 0,9(21,3-40,3)$ & 1,04 & $\begin{array}{c}\text { Prolato } \\
\text { esferoidal }\end{array}$ & 21,6 & 5,5 & 4,2 & 1,2 & 0,6 \\
\hline
\end{tabular}



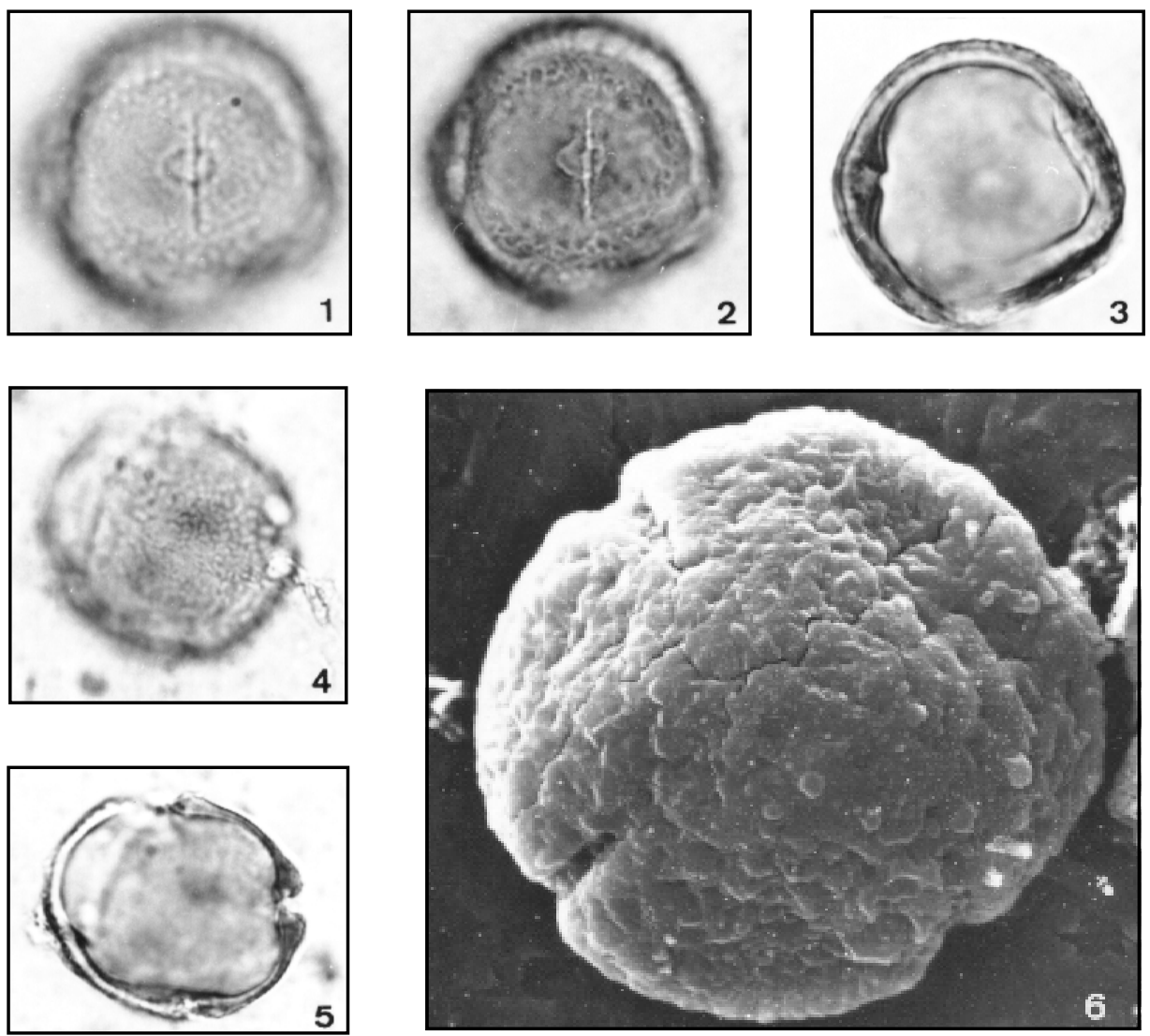

Figs. 1-6 - Cabralea canjerana. Fig. 1 - vista equatorial, superfície e abertura (ML); Fig. 2 - idem, foco mais baixo (ML); Fig. 3 - idem, corte óptico (ML); Fig. 4 - área polar, superfície (ML); Fig. 5 - vista polar, corte óptico (ML); Fig. 6 - vista polar, superfície, abertura e área polar. 3600X (MEV). ML $=1000 \mathrm{X}$.

Gênero Cedrela (Esquema 2, Figs. 7 a 22)

Características morfológicas comuns às espécies examinadas:

Forma do pólen: grãos de tamanho médio; simetria radial; isopolares; prolato esferoidais; amb circular a quadrangular; 4 - colporados; colpos estreitos com os ápices arredondados; endoaberturas lalongadas a circulares, com ânulo; superfície psilada; orbículos presentes nas preparações acetolisadas.

Estratificação da exina: a sexina não apresenta perfurações nem columelas distintas: a nexina-1 confunde-se com a sexina e é responsável pelo espessamento em volta das endoaberturas e ao longo dos colpos; a nexina-2 é distinta e de espessura constante, exceto sob os ânulos, quando freqüentemente se apresenta granulada.

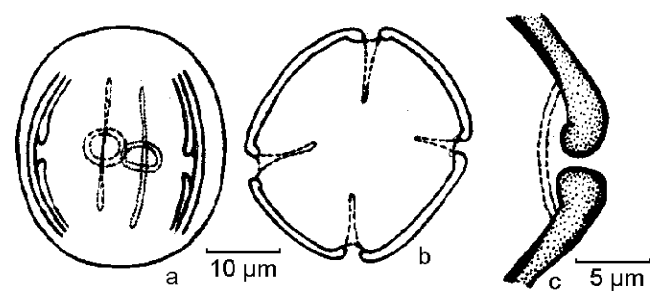

Esquema 2 - Cedrela fissilis, representante para o gênero: (a) vista equatorial: aberturas; (b) vista polar: amb, aberturas e corte óptico; (c) corte transversal pela exina e pelo centro de uma abertura.

\section{Gênero Guarea (Esquema 3; Figs. 23 a 35)}

Características morfológicas comuns às espécies examinadas:

Forma do pólen: grãos de tamanho médio a grande; simetria radial; isopolares; esferoidais; amb circular a quadrangular; 4 (-5) - colporados; 
TABELA 2

Gênem Cedrela: dimensões e forma dos grãos de pólen (em $\mu \mathrm{m})$ dos espécimens examinados.

\begin{tabular}{|c|c|c|c|c|c|c|c|c|c|}
\hline Nome da espécie & $\mathbf{P}$ & $\mathbf{E}$ & $\mathbf{P} / \mathbf{E}$ & Forma & $\mathbf{C}$ & $\mathbf{L}$ & $\mathbf{A}$ & $\mathrm{S}+\mathrm{N1}$ & $\mathbf{N 2}$ \\
\hline Cedrela fissilis & $33,5 \pm 0,4(28,4-37,2)$ & $30,0 \pm 0,4(24,8-34,9)$ & 1,11 & $\begin{array}{l}\text { Prolato } \\
\text { esferoidal }\end{array}$ & 22,9 & 6,5 & 5,1 & 1,0 & 0,6 \\
\hline C. lilloi & $38,3 \pm 0,7(31,7-44,3)$ & $34,6 \pm 0,7(28,0-42,6)$ & 1,10 & $\begin{array}{l}\text { Prolato } \\
\text { esferoidal }\end{array}$ & 30,1 & 7,0 & 4,4 & 1,3 & 0,6 \\
\hline C. odorata & $34,8 \pm 0,9(28,2-41,8)$ & $30,8 \pm 0,6(25,6-37,9)$ & 1,12 & $\begin{array}{l}\text { Prolato } \\
\text { esferoidal }\end{array}$ & 25,6 & 6,2 & 6,4 & 1,1 & 0,5 \\
\hline
\end{tabular}
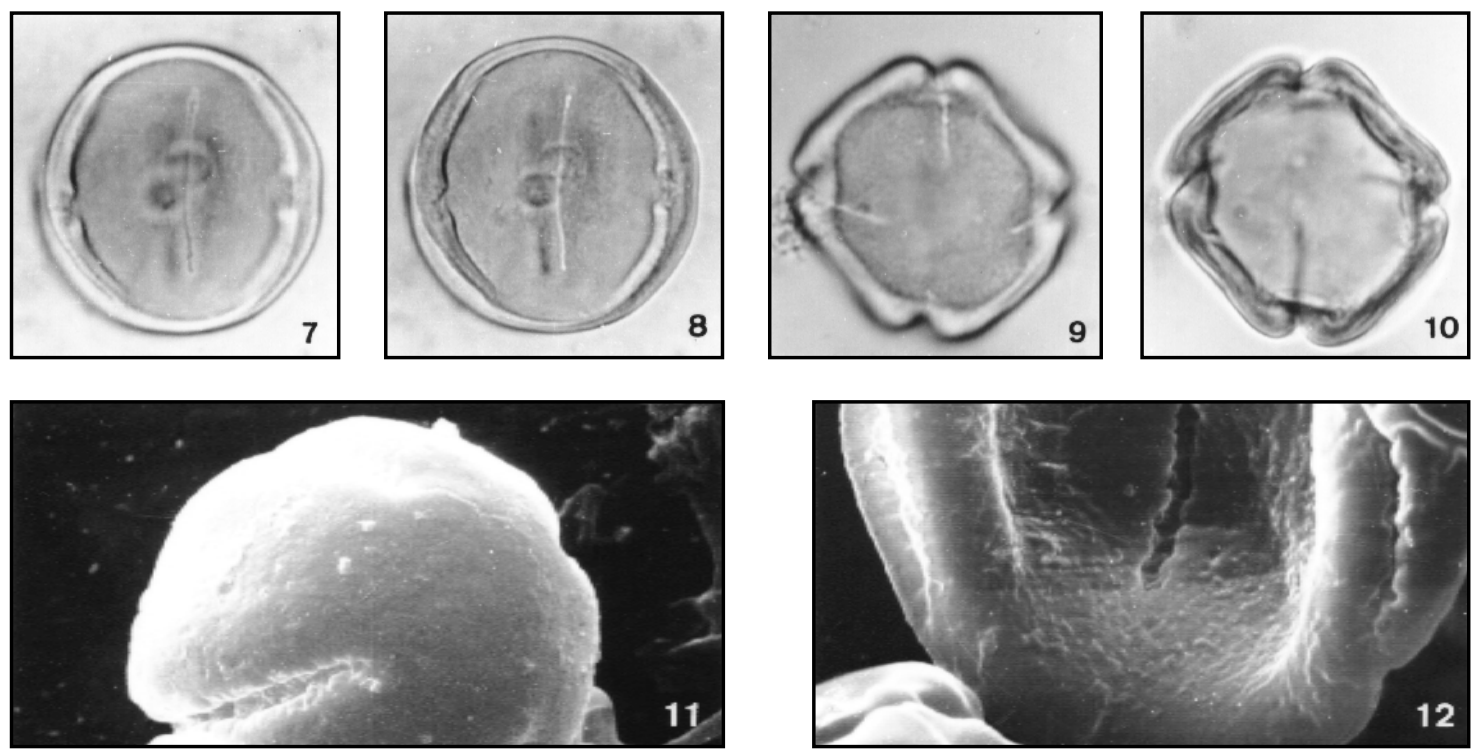

Figs. 7-12 - Cedrela fissilis. Fig. 7 - vista equatorial, superfície lisa e aberturas (ML); Fig. 8 - idem, corte óptico (ML); Fig. 9 - vista polar, superfície lisa e aberturas (ML): Fig. 10 - idem, corte óptico (ML); Fig. 11 — vista polar, superfície, 3600X (MEV); Fig. 12 — vista equatorial, detalhe da superfície e parte de uma abertura. 5400X (MEV). ML $=1000 X$.
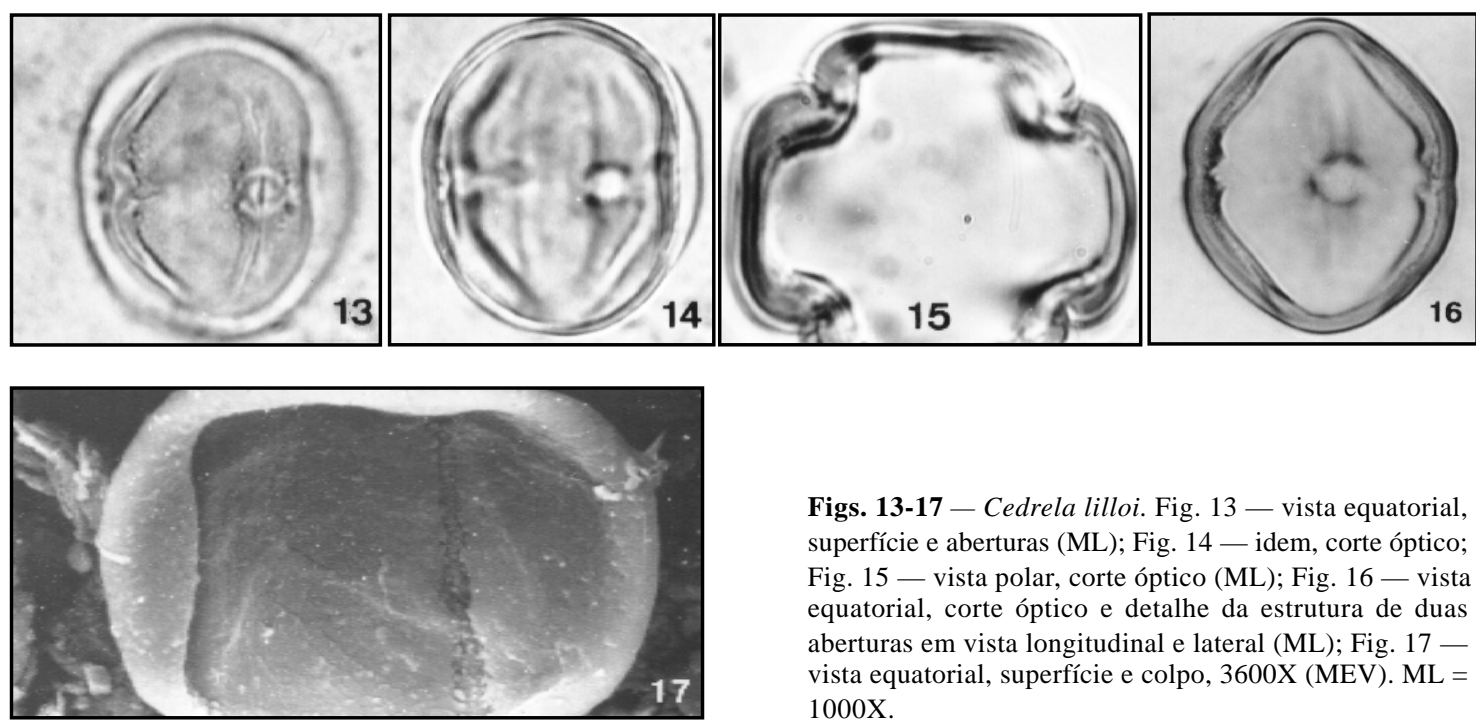

Figs. 13-17 - Cedrela lilloi. Fig. 13 - vista equatorial, superfície e aberturas (ML); Fig. 14 - idem, corte óptico; Fig. 15 - vista polar, corte óptico (ML); Fig. 16 - vista equatorial, corte óptico e detalhe da estrutura de duas aberturas em vista longitudinal e lateral (ML); Fig. $17-$ vista equatorial, superfície e colpo, 3600X (MEV). ML = $1000 \mathrm{X}$. 

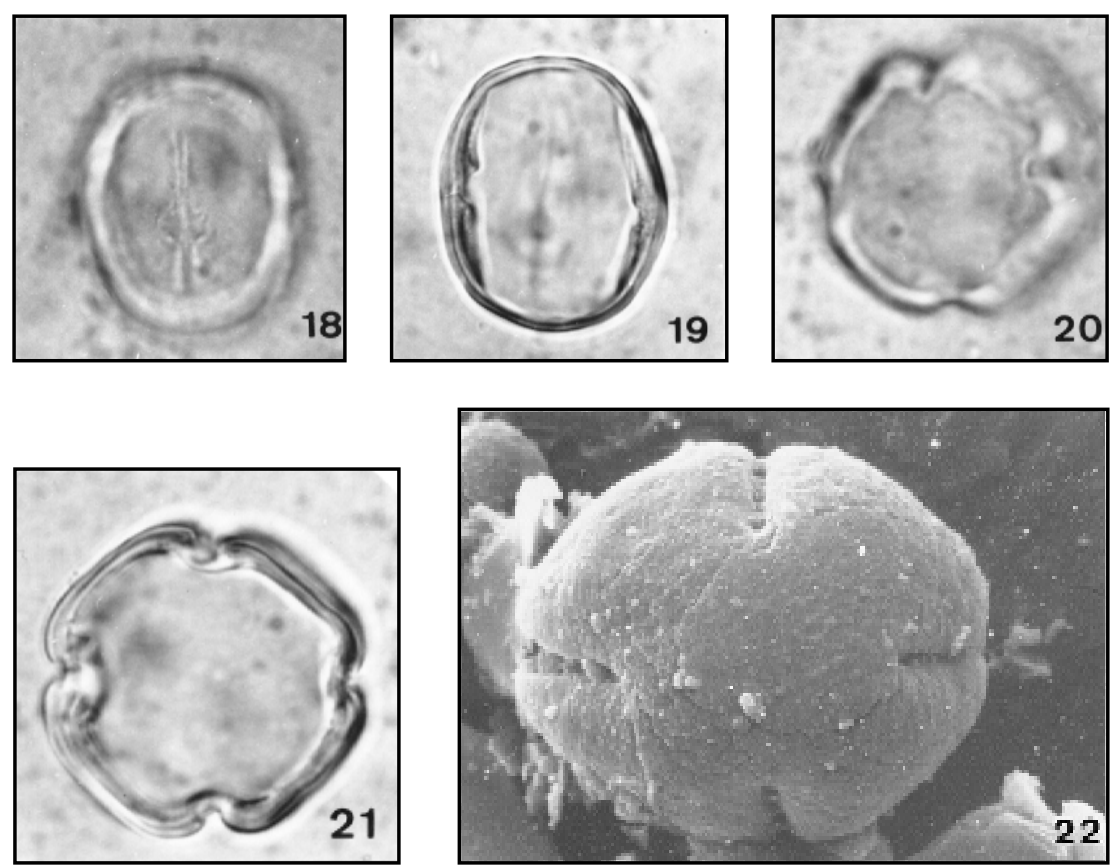

Figs. 18-22 - Cedrela odorata. Fig. 18 - vista equatorial, superfície e abertura (ML); Fig. 19 - idem, corte óptico (ML); Fig. 20 - vista polar, superfície (ML); Fig. 21 — idem, corte óptico; Fig. 22 — vista polar. área polar, superfície e aberturas, $3600 X(\mathrm{MEV}) . \mathrm{ML}=1000 \mathrm{X}$.

colpos estreitos; brevicolpados; endoaberturas lalongadas a circulares; superfície psilada; orbículos ausentes nas preparações acetolisadas.

Estratificação da exina: a sexina não apresenta perfurações nem columelas distintas; entretanto, há uma separação visível entre sexina e nexina-1; a nexina-1 é responsável pela formação dos ânulos em volta das endoaberturas; a nexina-2 é de espessura constante.

Gênero Trichilia (Esquema 4, Figs. 36 a 68)

Características morfológicas comuns às espécies examinadas:
Forma do pólen: grãos de tamanho médio; simetria radial; isopolares; subprolatos a prolatos; amb subtriangular, circular ou quadrangular de vértices arredondados; (3-) 4 (-5) - colporados; colpos estreitos; endoaberturas lalongadas, de formatos variáveis, com ânulo pouco pronunciado; superfície psilada, às vezes com pontuações visíveis; orbículos ausentes nas preparações acetolisadas.

Estratificação da exina: a sexina é tectada, apresentando perfurações no teto e delgadas columelas; é mais espessa que a nexina (nexina-1 + nexina-2); a nexina-1 é mais espessa em vol-

TABELA 3

Gênero Guarea: dimensões e forma dos grãos de pólen (em $\mu \mathrm{m})$ dos espécimens examinados.

\begin{tabular}{|c|c|c|c|c|c|c|c|c|c|c|}
\hline Nome da espécie & $\mathbf{P}$ & $\mathbf{E}$ & $\mathbf{P} / \mathbf{E}$ & Forma & $\mathrm{C}$ & $\mathbf{L}$ & $\mathbf{A}$ & $\mathbf{S}$ & N1 & N2 \\
\hline Guarea kunthiana & $47,5 \pm 0,4(44,8-53,0)$ & $51,3 \pm 0,5(47,6-56,9)$ & 0,92 & $\begin{array}{l}\text { Oblato } \\
\text { esferoidal }\end{array}$ & 21,8 & 11,0 & 9,2 & 0,7 & 0,7 & 0,6 \\
\hline $\begin{array}{l}\text { G. macrophylla ssp. } \\
\text { spicaeflora }\end{array}$ & $33,1 \pm 0,7(27,1-39,2)$ & $31,5 \pm 0,6(25,3-36,1)$ & 1,05 & $\begin{array}{l}\text { Prolato } \\
\text { esferoidal }\end{array}$ & 10,5 & 3,5 & 3,6 & 0,8 & 1,1 & 0,6 \\
\hline $\begin{array}{l}\text { G. macrophylla ssp. } \\
\text { tuberulata }\end{array}$ & $40,0 \pm 0,4(36,4-43,8)$ & $44,2 \pm 0,4(41,0-47,6)$ & 0,90 & $\begin{array}{l}\text { Oblato } \\
\text { esferoidal }\end{array}$ & 15,5 & 10,1 & 7,3 & 0,7 & 0,7 & 0,6 \\
\hline
\end{tabular}


ta das endoaberturas e ao longo dos colpos (costas), mas quase ausente nas áreas polares; a nexina-2 é de espessura constante.

Não foi possível separar os grãos de pólen das espécies examinadas pela sua forma. Freqüentemente, o formato das endoaberturas parece estar ligado à espécie. Entretanto, observações de um número crescente de grãos de pólen levam a encontrar diversos formatos em cada espécie.

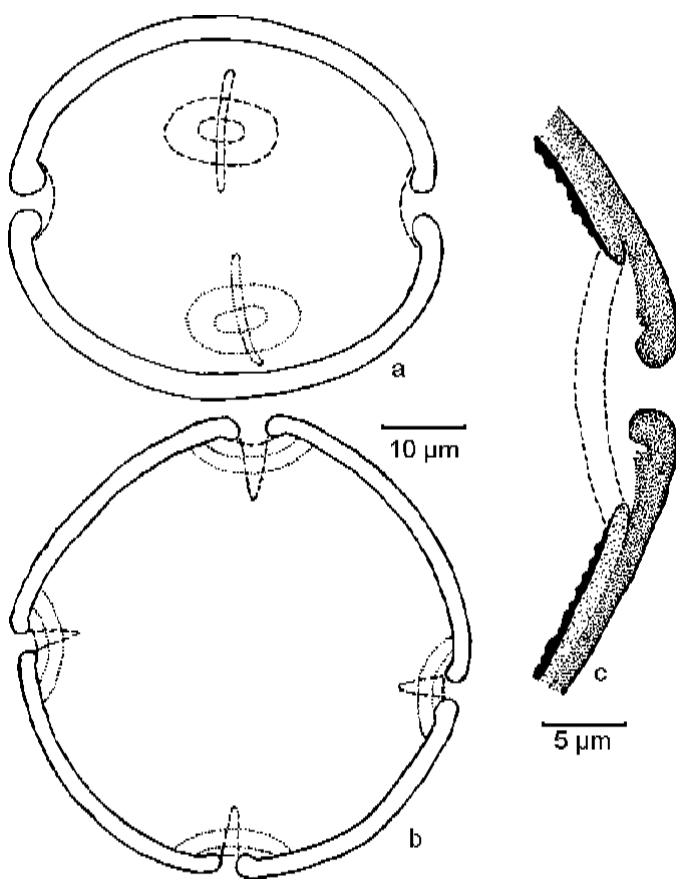

Esquema 3 - Guarea kunthiana, representante para o gênero: (a) vista oblíqua: aberturas e corte óptico pela exina; (b) vista polar: amb, aberturas e corte óptico; (c) corte transversal pela exina e pelo centro de uma abertura.

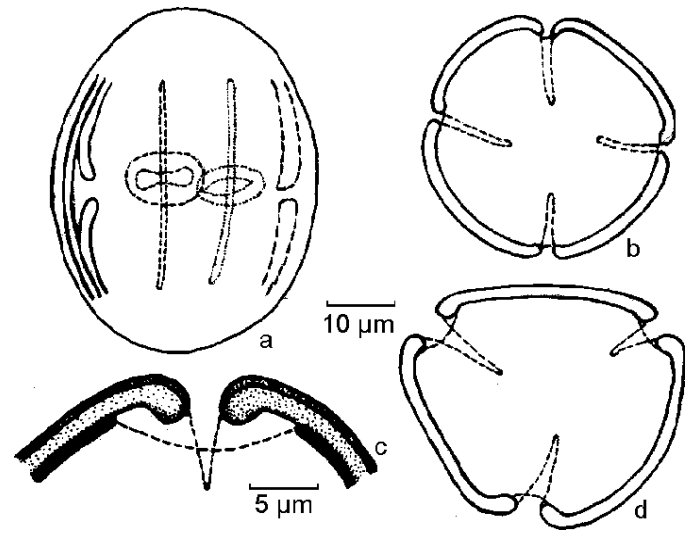

Esquema 4 - Trichilia lepidota, representante para o gênero: (a) vista equatorial: aberturas; (b) vista polar de um grão 4-colporado: amb, aberturas e corte óptico; (c) corte transversal pela exina e pelo centro de uma abertura (perfurações do teto e finíssimas columelas não representáveis no presente aumento); (d) vista polar de um grão 3-colporado: amb, aberturas e corte óptico.

\section{DISCUSSÃO}

Em nível de microscopia de luz, não é possível distinguir morfologicamente os grãos de pólen das espécies estudadas dentro de um mesmo gênero, de modo que a morfologia polínica limita-se à caracterização genérica.

A morfologia dos grãos de pólen das espécies aqui examinadas e dos tipos polínicos estabelecidos corresponde à separação das espécies nos gêneros aqui abordados. As diferenças mais marcantes entre os tipos polínicos são: (1) a presença de teto, delgadas columelas e a sexina mais espessa que a nexina no gênero Trichilia, enquanto nos demais gêneros abordados as columelas da sexina são indistintas; (2) as espécies estudadas

TABELA 4

Gênero Trichilia: dimensões e forma dos grãos de pólen (em $\mu \mathrm{m})$ dos espécimens examinados.

\begin{tabular}{|c|c|c|c|c|c|c|c|c|c|}
\hline Nome da espécie & $\mathbf{P}$ & $\mathbf{E}$ & $\mathbf{P} / \mathbf{E}$ & Forma & C & $\mathbf{L}$ & $\mathbf{A}$ & $\mathbf{S}^{*}$ & N21 \\
\hline Trichilia casaretti & $31,5 \pm 0,5(27,4-36,1)$ & $23,3 \pm 0,4(19,2-27,7)$ & 1,35 & Prolato & 23,3 & 7,0 & 2,4 & 1,1 & 0,6 \\
\hline T. catigua & $32,8 \pm 0,2(30,2-34,4)$ & $28,1 \pm 0,2(25,7-30,7)$ & 1,16 & Subprolato & 22,5 & 8,4 & 3,8 & 1,0 & 0,6 \\
\hline T. clausseni & $35,0 \pm 0,3(32,6-38,5)$ & $27,8 \pm 0,3(24,6-31,8)$ & 1,25 & Subprolato & 22,2 & 7,3 & 3,0 & 1,0 & 0,5 \\
\hline T. elegans ssp. elegans & $33,5 \pm 0,3(30,5-36,4)$ & $27,2 \pm 0,3(23,9-30,2)$ & 1,23 & Subprolato & 22,6 & 7,3 & 3,8 & 1,1 & 0,6 \\
\hline $\begin{array}{l}\text { T. lepidota ssp. } \\
\text { schumanniana }\end{array}$ & $36,0 \pm 0,3(32,8-39,0)$ & $29,7 \pm 0,3(27,4-32,0)$ & 1,21 & Subprolato & 26,0 & 8,5 & 4,1 & 1,2 & 0,6 \\
\hline T. pallens & $33,5 \pm 0,4(29,8-38,4)$ & $26,1 \pm 0,3(23,3-30,0)$ & 1,28 & Subprolato & 26,4 & 8,1 & 4,2 & 1,0 & 0,6 \\
\hline T. pallida & $35,4 \pm 0,6(27,2-39,2)$ & $26,4 \pm 0,5(20,3-30,3)$ & 1,34 & Prolato & 23,5 & 6,6 & 4,0 & 1,0 & 0,5 \\
\hline T. pseudostipularis & $34,2 \pm 0,5(30,8-40,7)$ & $29,7 \pm 0,6(23,6-34,9)$ & 1,15 & Subprolato & 25,1 & 9,6 & 2,4 & 1,0 & 0,5 \\
\hline T. silvatica & $29,9 \pm 0,5(25,1-35,1)$ & $24,7 \pm 0,4(20,8-28,5)$ & 1,21 & Subprolato & 21,3 & 6,3 & 2,6 & 1,0 & 0,5 \\
\hline
\end{tabular}

* Inclui a nexina-1, caso haja vestígios. 
apresentaram grãos de pólen com 4 aberturas como número proporcionalmente predominante em cada taxa, exceto em Trichilia pseudostipularis e T. silvatica, predominando grãos com somente 3 aberturas; (3) um ânulo expressivo caracteriza os grãos de pólen dos gêneros Cabralea e Guarea; entretanto, os grãos de pólen deste último gênero são brevicolpados; (4) pequeno espessamento da nexina-1 em volta das endoaberturas em Cedrela; (5) uma exina verrugosa em Cabralea. As endoaberturas dos grãos de pólen das espécies estudadas têm formatos variados, não caracterizando os tipos polínicos

Em relação ao material polínico examinado por outros autores (Carreira \& Secco, 1984; Silvestre-Capelato et al., 1996), pudemos verificar que, quanto às características dos tipos polínicos, os dados conferem. Há divergências quanto à espessura das diversas camadas componentes da exina, já que o limite entre sexina e nexina-1 nos gêneros Cabralea e Cedrela não é distinto; a nexina-2 sempre se destaca bem por sua birrefringência, e sua espessura mantém-se constante. Os dados aqui obtidos relativos às espécies Cabralea canjerana e Cedrela fissilis são similares aos encontrados por Silvestre-Capelato et al. (1996); o mesmo ocorreu com o material de Cedrela odorata examinado por Carreira \& Secco (1984) e Roubik \& Moreno (1991). Os grãos de pólen das três espécies de Cedrela aqui estudados são inseparáveis morfologicamente. Todas as três espécies apresentam numerosos orbículos junto aos grãos de pólen nas preparações acetolisadas, fato também citado para Cedrela odorata por Carreira \& Secco (1984); orbículos nunca foram observados nos demais gêneros analisados no presente trabalho.

As descrições dos grãos de pólen de Guarea macrophylla apresentadas por Silvestre-Capelato et al. (1996) conferem com os nossos dados. Verificamos que, no caso das Meliaceae, os espessamentos que ocorrem em volta das endoaberturas correspondem a um ânulo, dizendo respeito ao espessamento da nexina (bem nítido em Guarea); formações de áspides e vestíbulos não ocorrem nas espécies de Meliaceae examinadas.

Quanto à ornamentação da exina, há variações no gênero Trichilia: os grãos de pólen de $T$. casaretti, T. catigua, T. clausseni, T. elegans, $T$. pallida, T. pseudostipularis e T. silvatica apresentam uma superfície perfurada, $T$. lepidota, finamente estriada e $T$. pallens, rugulada, quando observados em grandes aumentos.

Os grãos de pólen de três das nove espécies examinadas de Trichilia foram também estudados por outros autores: os de T. lepidota schumanniana e T. silvatica por Silvestre-Capelato et al. (1996) e de T. pallida por Roubik \& Moreno (1991); os resultados conferem com os nossos, havendo somente variações quanto às medidas dos eixos polares, não interferindo na forma dos grãos.
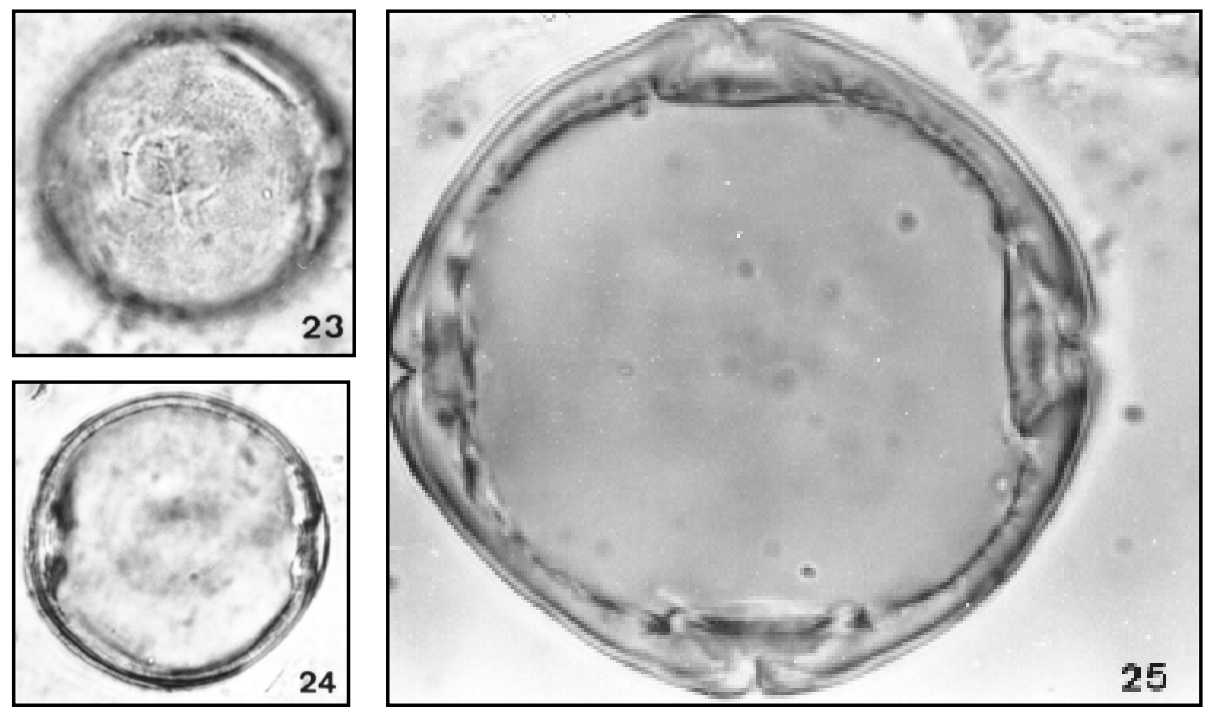

Figs. 23-25 - Guarea kunthiana. Fig. 23 - vista equatorial, superfície e abertura, 1000X (ML); Fig. 24 - idem, corte óptico, 1000X (ML); Fig. 25 — vista polar, corte óptico, 1300X (ML). 

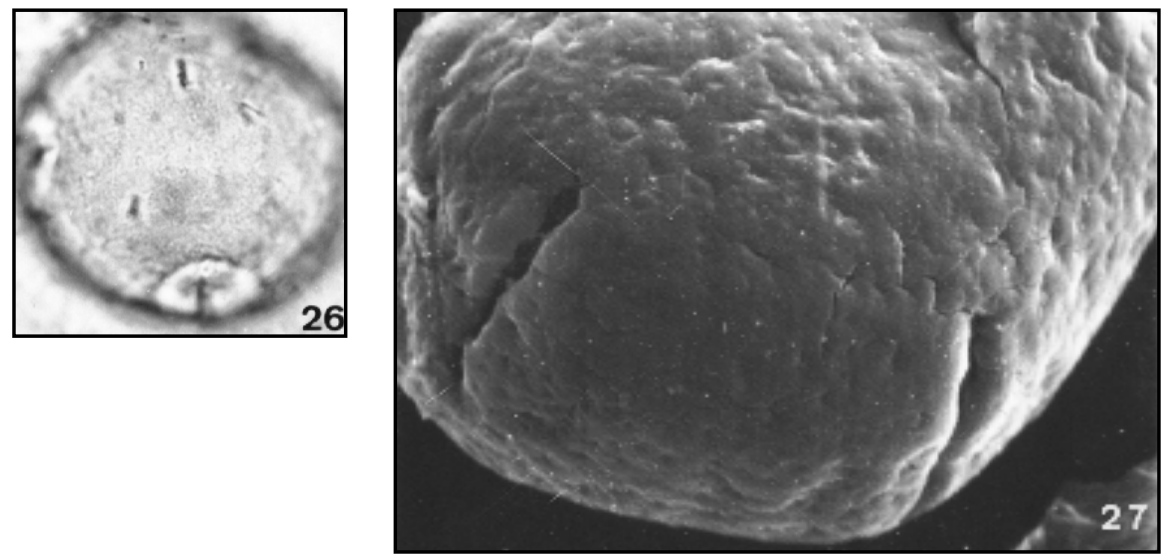

Figs. 26-27 - Guarea kunthiana. Fig. 26 - vista polar, superfície, 700X (ML); Fig. 27 — vista oblíqua, superfície e colpos, 4120X (MEV).
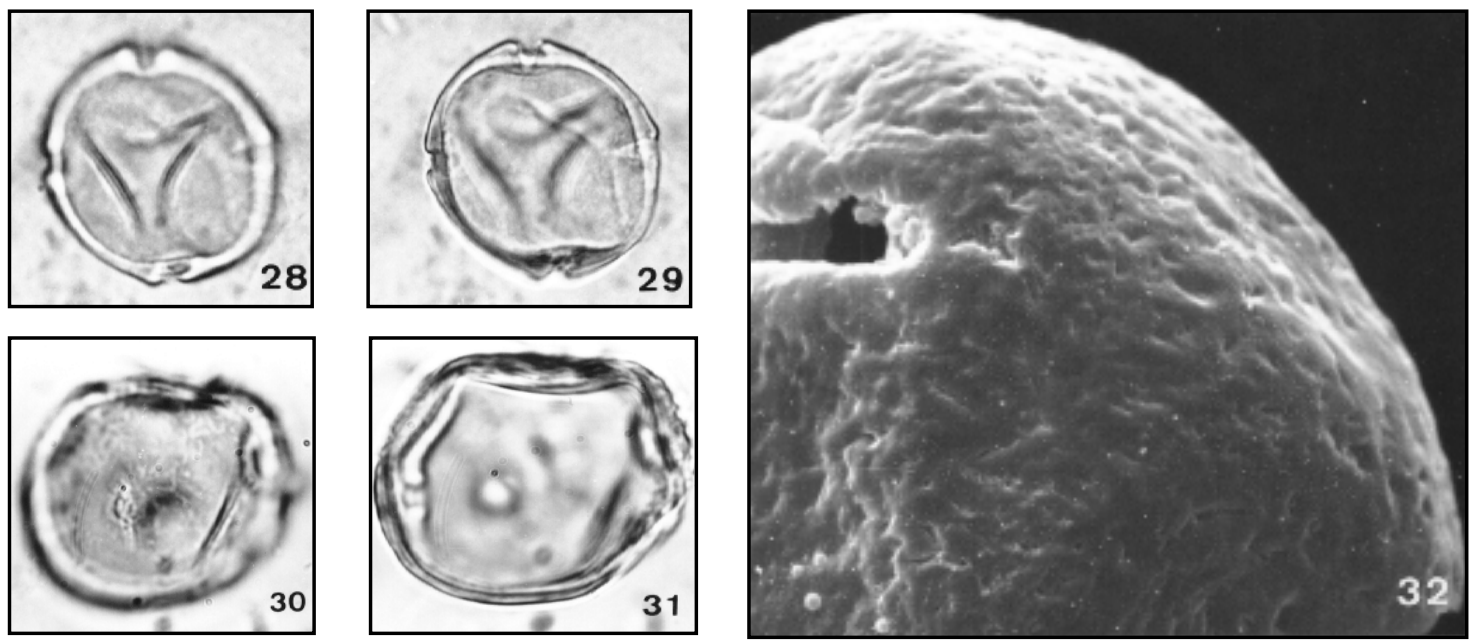

Figs. 28-32 - Guarea macrophylla ssp. spicaeflora. Fig. 28 - vista polar, superfície com dobras (ML); Fig. 29 - idem, corte óptico (ML); Fig. 30 - vista equatorial, superfície e abertura (ML); Fig. 31 — idem, corte óptico (ML); Fig. 32 vista oblíqua, superfície da área polar e parte de uma abertura, 5400X (MEV). ML = 1000X.
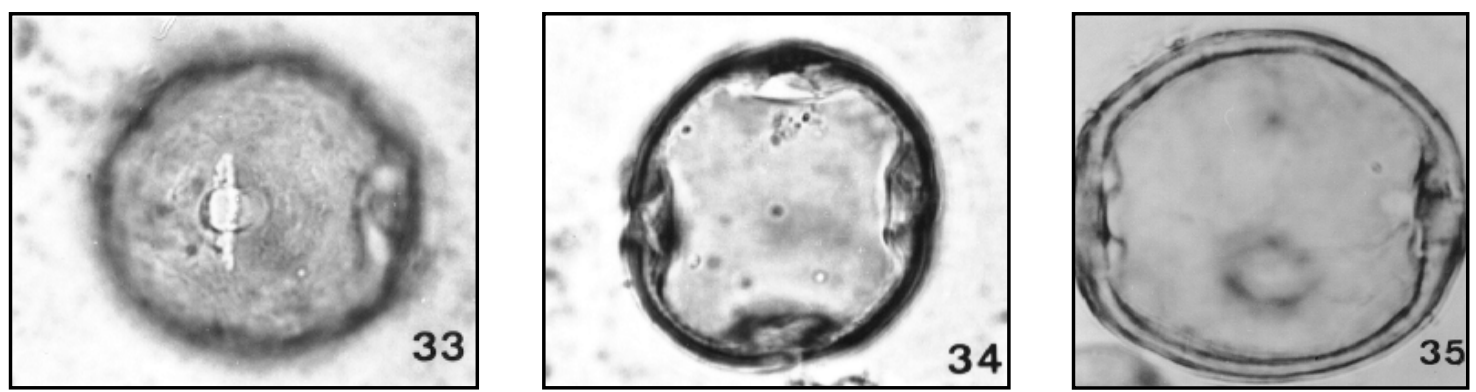

Figs. 33-35 - Guarea macrophylla ssp. tuberculata. Fig. 33 - vista equatorial, superfície e abertura (ML); Fig 34 - vista polar, corte óptico (ML); Fig. 35 - vista equatorial, corte óptico (ML). ML = 1000X. 

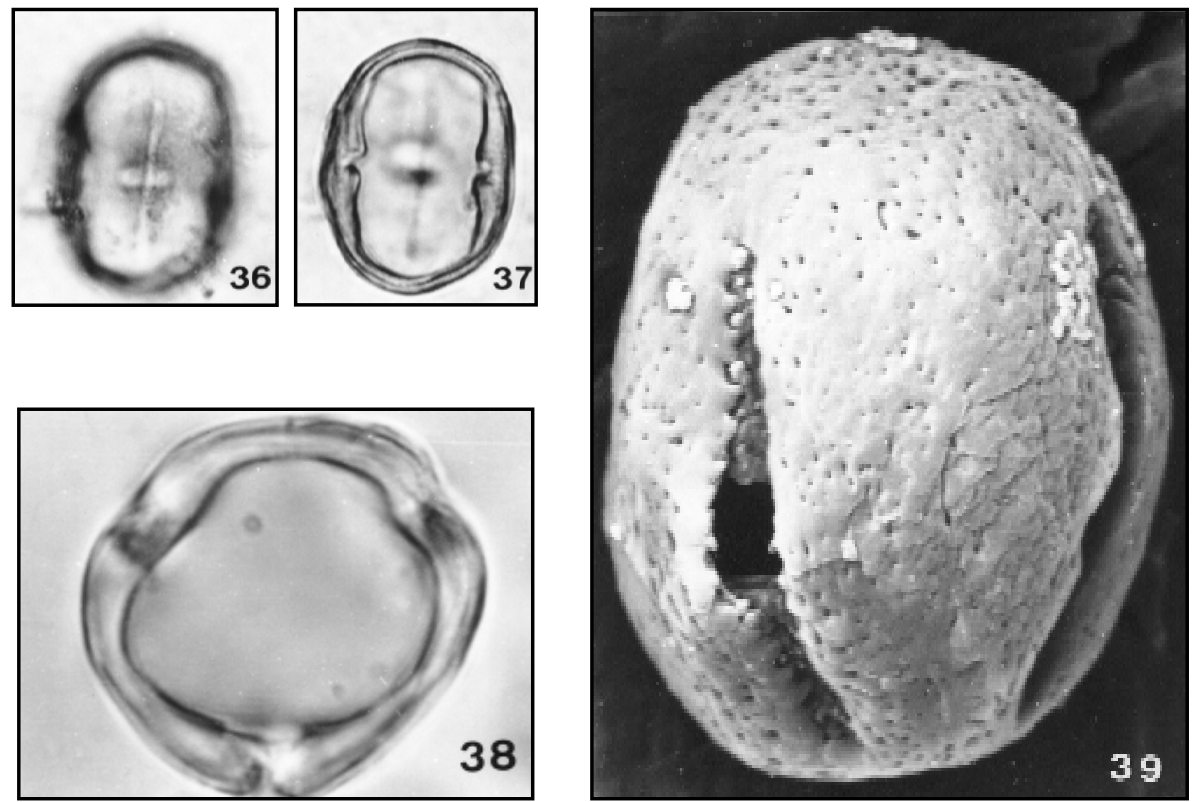

Figs. 36-39 - Trichilia catigua. Fig. 36 - vista equatorial, superfície e abertura (ML); Fig. 37 — idem, corte óptico (ML); Fig. 38 - vista polar, corte óptico (ML); Fig. 39 - vista equatorial, superfície perfurada e aberturas, 5400X (MEV). ML = 1000X.
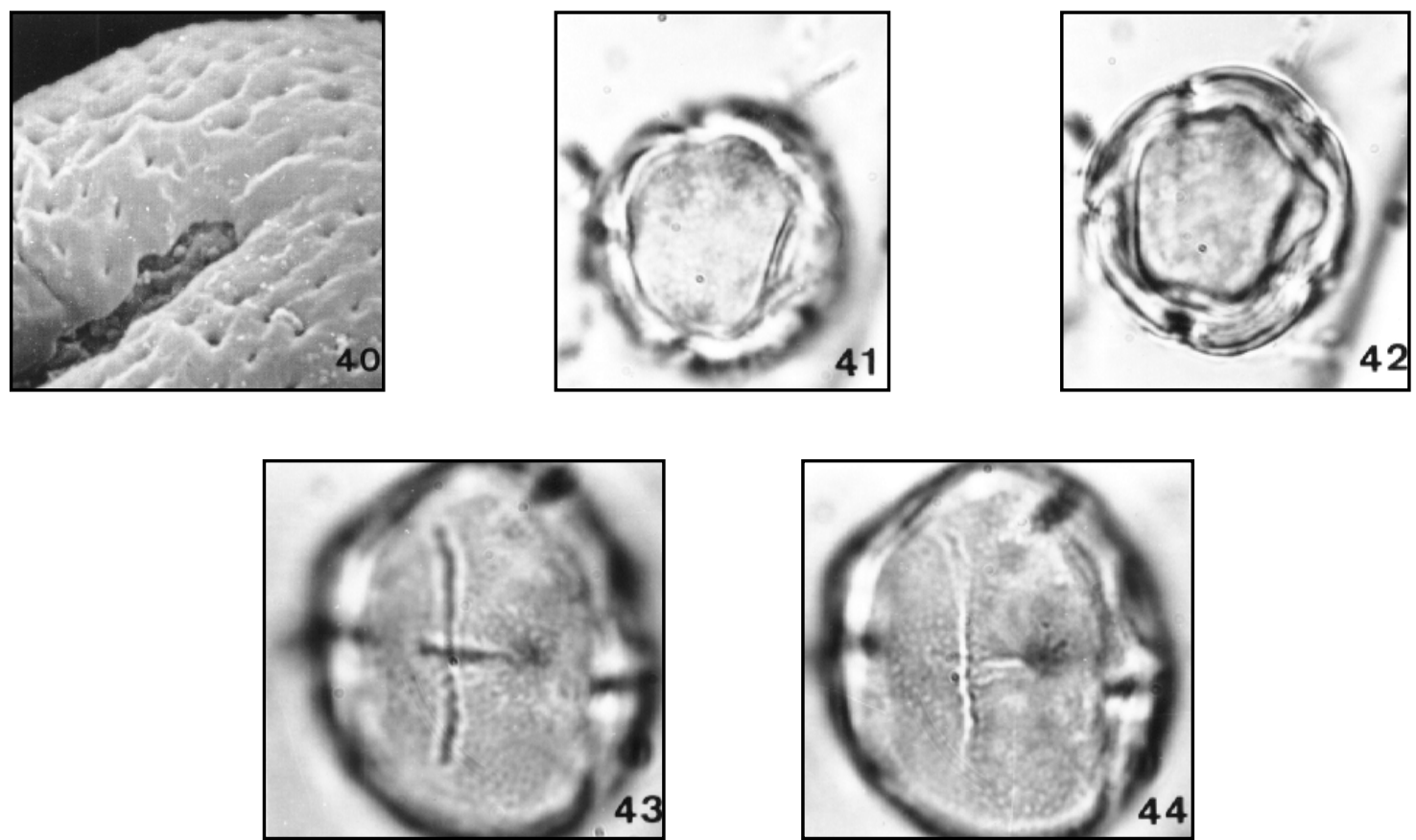

Figs. 40-44 - Trichilia clausseni. Fig. 40 — superfície perfurada e parte de um colpo, 9000X (MEV); Fig. 41 — vista polar, superfície (ML); Fig. 42 - idem, corte óptico (ML); Fig. 43 - vista equatorial, superfície e abertura (ML); Fig. 44 - idem, foco mais baixo (ML). $\mathrm{ML}=1000 \mathrm{X}$. 

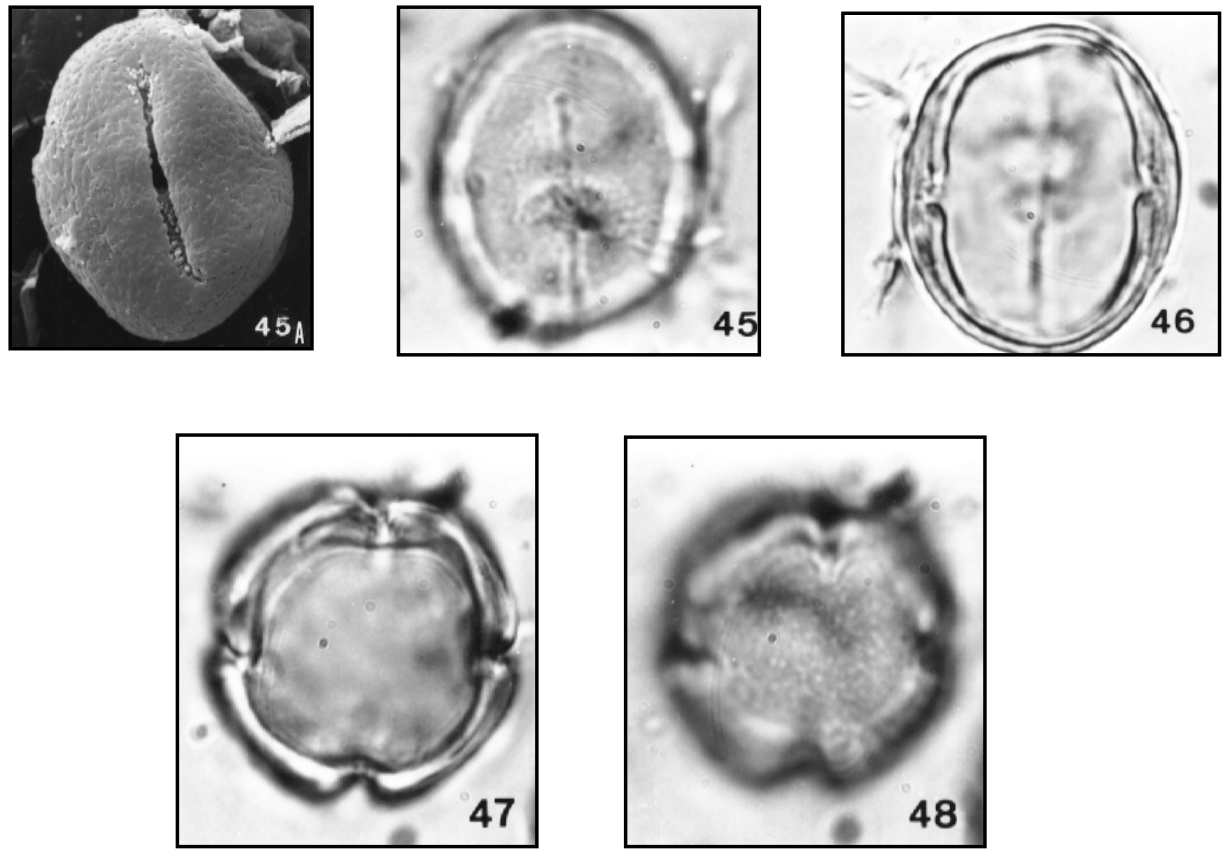

Figs. 45-48 - Trichilia elegans. Fig. 45 A — vista equatorial, superfície perfurada e abertura. 3000X (MEV); Fig. 45 idem (ML); Fig. 46 — idem, corte óptico (ML); Fig. 47 - vista polar, corte óptico (ML); Fig. 48 — idem, superfície. ML = 1000X.
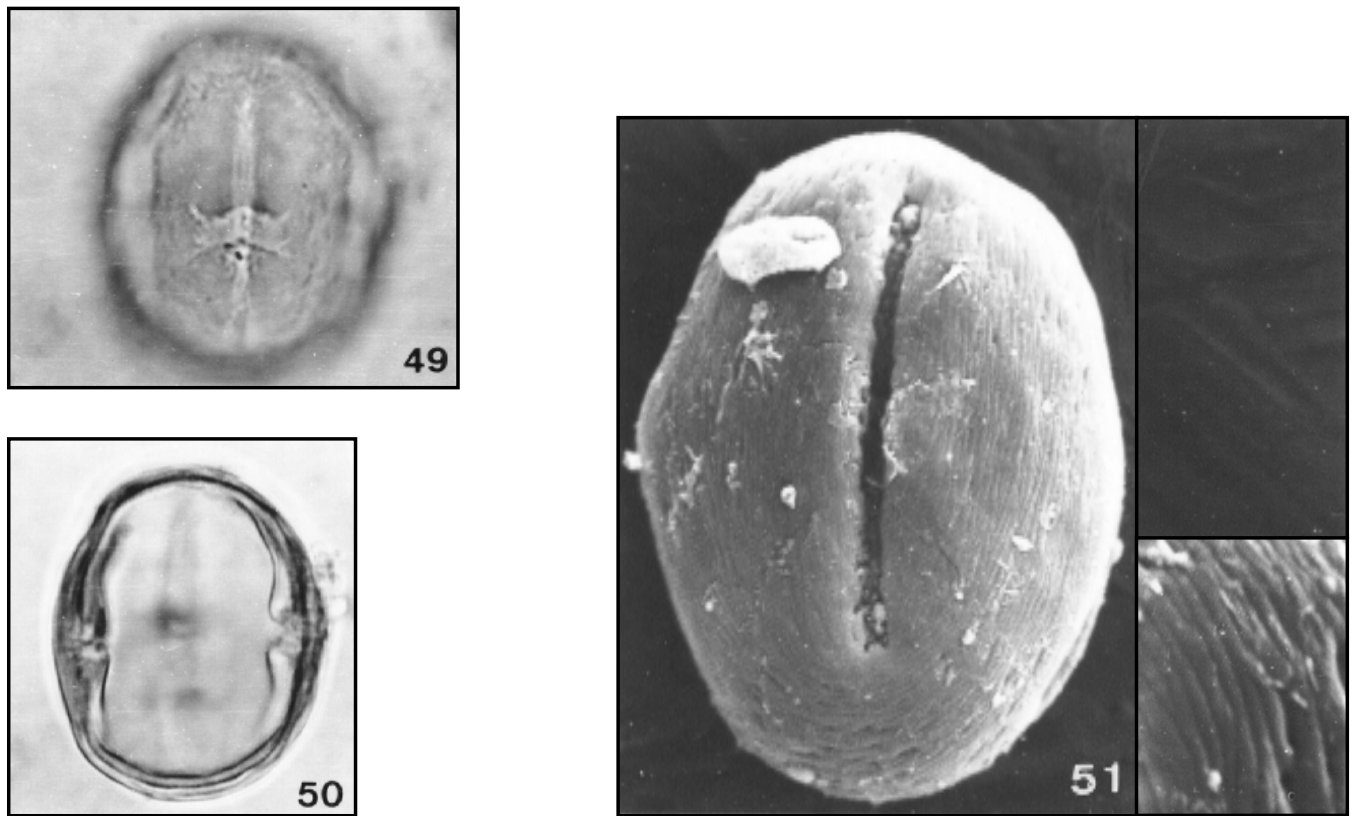

Figs. 49-51 - Trichilia lepidota. Fig. 49 - vista equatorial, superfície e abertura (ML); Fig. 50 - idem, corte óptico (ML); Fig. 51 - vista equatorial, superfície estriada e abertura, 3600X e estrias em maior aumento, 9000X (MEV). ML = 1000X. 

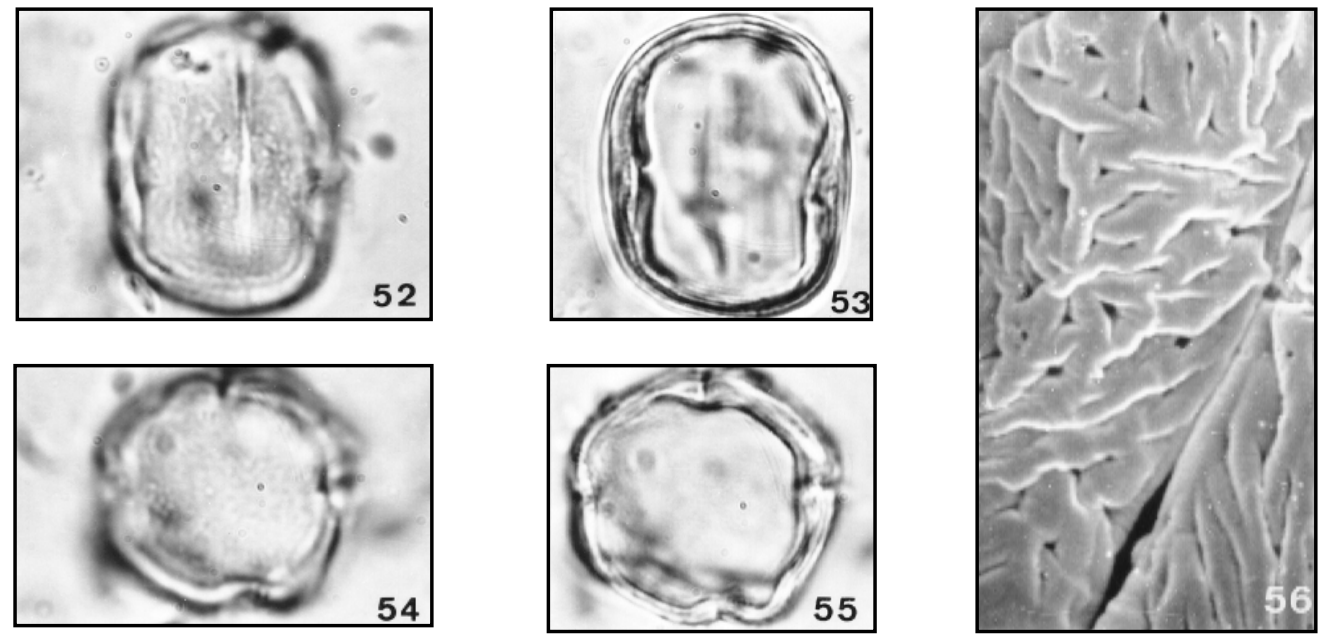

Figs. 52-56 - Trichilia pallens. Fig. 52 - vista equatorial, superfície e abertura (ML); Fig. 53 — idem, corte óptico (ML); Fig. 54 - vista polar, superfície (ML); Fig. 55 - idem, corte óptico (ML); Fig. 56 - superf ície rugulada na região equatorial, $10.000 \mathrm{X}(\mathrm{MEV}) . \mathrm{ML}=1000 \mathrm{X}$.
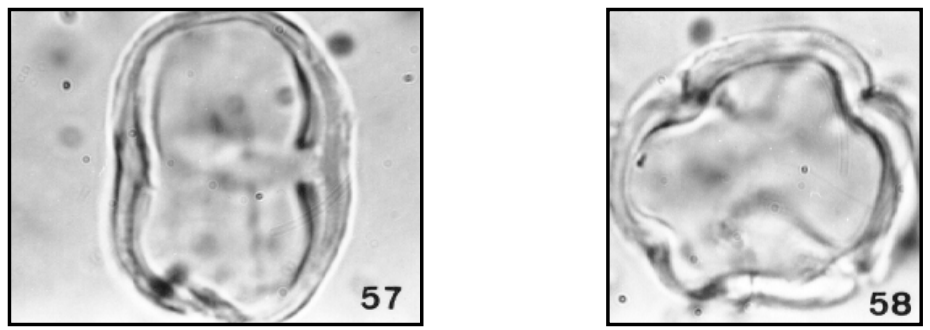

Figs 57-58 - Trichilia pallida. Fig. 57 - vista equatorial, corte óptico (ML); Fig. 58 — vista polar, corte óptico (ML). $\mathrm{ML}=1000 \mathrm{X}$.
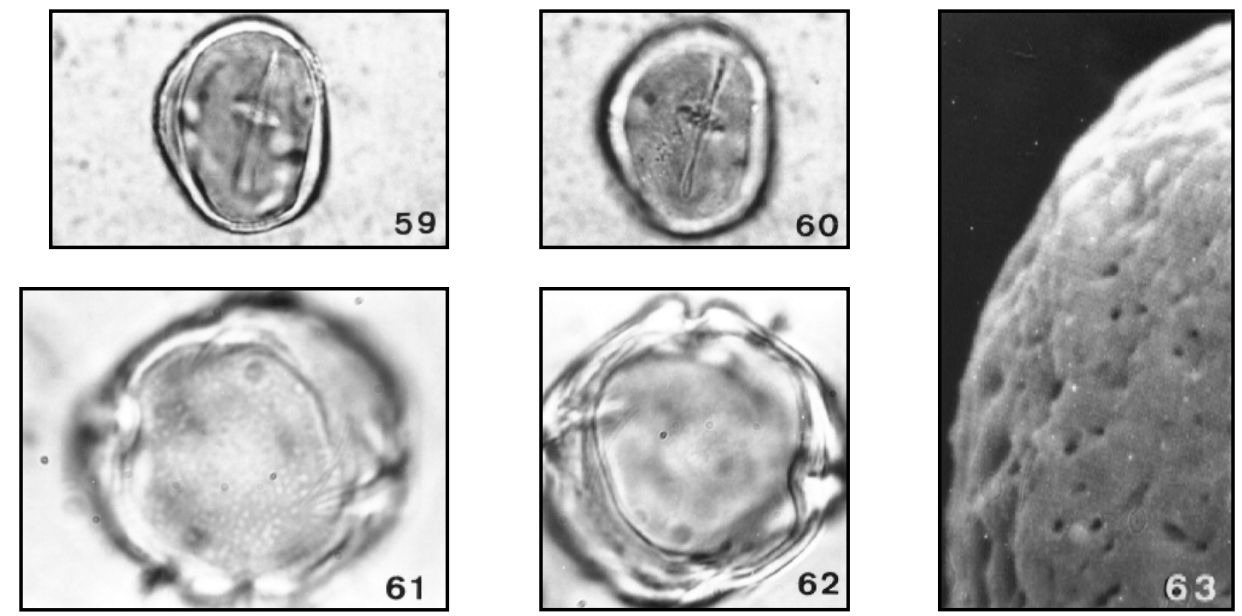

Figs. 59-63 - Tric hilia pseudostipularis. Fig. 59 - vista equatorial, corte óptico (ML); Fig. 60 - idem, superfície e abertura (ML); Fig. 61 - vista polar, superfície (ML); Fig. 62 - idem, corte óptico (ML); Fig. 63 - detalhe da superfície perfurada, $10.000 \mathrm{X}(\mathrm{MEV}) . \mathrm{ML}=1000 \mathrm{X}$. 

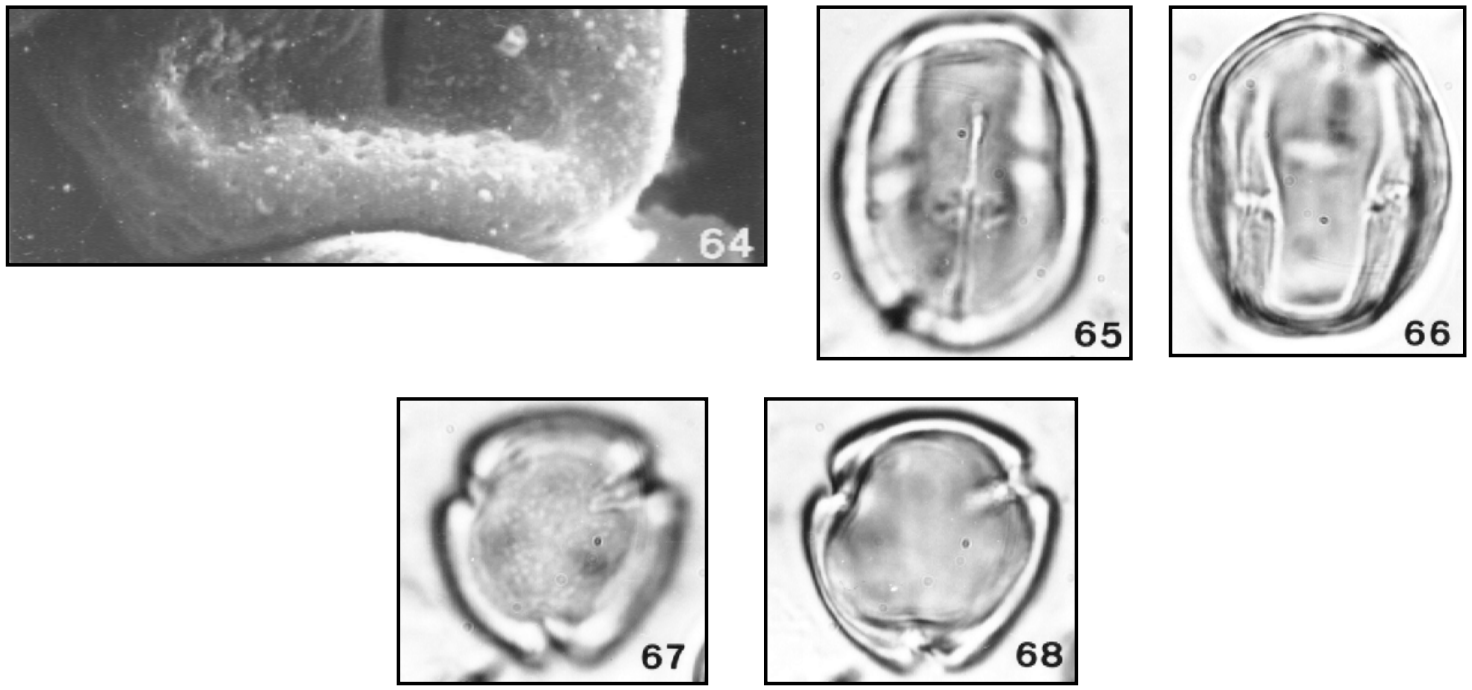

Figs. 64-68 - Trichilia silvatica. Fig. 64 - detalhe da superfície perfurada, 9000X (MEV); Fig. 65 - vista equatorial, superfície e abertura (ML); Fig. 66 - idem, corte óptico (ML); Fig. 67 - vista polar, superfície (ML); Fig. 68 - idem, corte óptico. $\mathrm{ML}=1000 \mathrm{X}$.

Agradecimentos - À fotógrafa Maria da Penha R. Costa do Departamento de Virologia, Instituto Oswaldo Cruz, FIOCRUZ, pela execução das ampliações fotográficas; ao CNPq; e à FAPERJ pelo apoio financeiro.

\section{REFERÊNCIAS BIBLIOGRÁFICAS}

BARROS, M. A. de \& BARTH, O. M., 1994, Catálogo sistemático do pólen das plantas arbóreas do Brasil meridional. XXVIII - Burseraceae e Clethraceae. Rev. Brasil. de Biol., 54(2): 317-322.

BARTH, O. M. \& MELHEM, T. S., 1988, Glossário Ilustrado de Palinologia. Campinas, UNICAMP, 75p.

BONNEFILlE, R. \& RIOLlET, G., 1980, Pollens des savanes d'Afrique orientale. C.N.R.S., Paris, 140p., $113 \mathrm{pl}$.

CARREIRA, L. M. M. \& SECCO, R. de S., 1984, Morfologia polínica de plantas cultivadas no Parque do Museu Goeldi - III. Meliaceae. Bol. Mus. Paraense Emílio Goeldi, Bot., 1(1-2): 5-22.

CRONQUIST, A., 1988, The evolution and classification of flowering plants. Lawrence, Printed by Allen Press, Inc., $555 \mathrm{p}$.

ERDTMAN, G., 1952, Pollen morphology and plant taxonomy. Chronica Botânica Co., Waltham, Mass, 539p.
FERREIRA A. G. \& LABOURIAU, M. L. S., 1966, Pollen grains of plants of the "Cerrado" - XV. Aquifoliaceae. Flacourtiaceae and Meliaceae. Bol. Mus. Paraense Emílio Goeldi, Bot., 24: 1-11.

KLEIN, R. M., 1984, Meliáceas. In: R. Reitz (ed.), Flora Ilustrada Catarinense - I Parte. R. Reitz ed. Itajaí, 138p.

MARKGRAF, V. \& D'ANTONI, H. L., 1978, Pollen Flora of Argentina. Tucson, Univ. Arizona Press, 208p.

PALÁCIOS, Ch. R., 1968, Morfologia de los Granos de Pólen de Arbores del Estado de Morelos. An. Esc. Nac. Cienc. Biol., 16: 41-169.

ROUBIK. D. W. \& MORENO, J. E., 1991, Pollen and Spores of Barro Colorado Island. Monographs in Sistematic Botany from the Missouri Botanical Garden, 36, 270p.

SCHEEL, R. \& BARTH, O. M., 1995, Catálogo sistemático do pólen das plantas arbóreas do Brasil meridional. XXIX - Boraginaceae. Rev. Brasil. de Biol., 55(4): 769-776.

SILVESTRE-CAPELATO, M. S. F., CRUZ-BARROS, M. A. V. da \& RODRIGUES, A. A. G., 1996, Flora Polínica da Reserva do Parque Estadual das Fontes do Ipiranga (São Paulo, Brasil). Família: 117 Meliaceae. Hoehnea, 23(1): 135-140. 